\title{
Elements of a Supportive Learning Environment for Mathematics Learners
}

\author{
Pragashni Padayachee (Corresponding author) \\ Department of Mathematics and Applied Mathematics, NMMU \\ South Africa \\ E-mail: pragashni.padayachee@nmmu.ac.za
}

Hennie Boshoff

Govan Mbeki Mathematics Development Unit

South Africa

E-mail: hennie.boshoff@nmmu.ac.za

\begin{abstract}
Ansie Harding
Department of Mathematics, University of Pretoria

South Africa

E-mail: ansie.harding@up.ac.za
\end{abstract}

Hermien Johannes

Centre for Teaching, Learning and Media, NMMU

South Africa

E-mail: hermien.johannes@nmmu.ac.za

Received: March 25, 2014 Accepted: May 23, 2014 Published: July 10, 2014

doi:10.5296/ire.v2i2.5776 URL: http://dx.doi.org/10.5296/ire.v2i2.5776 


\section{Abstract}

South Africa is witnessing an education crisis of significant proportions and universities are suffering the consequences of under preparation of learners for tertiary studies especially in mathematics. It has become common practice for universities to deploy augmented programmes in mathematics for secondary school learners in the surrounding areas. This article reports on an intervention in the Eastern Cape of South Africa, called the Incubator School Project (ISP) an initiative of the Nelson Mandela Metropolitan University. The defining feature of the ISP is that it incorporates DVD technology that offers an affordable and accessible option for the particular group of learners and the schools they attend. The article considers the research question: What elements present in this intervention support the teaching and learning of mathematics?

This case study within an action research project explores the particular blended approach and reports qualitatively based firstly on a questionnaire completed by learners, secondly on interviews of learners, and thirdly on the facilitators reports.

This research revealed that using the DVD approach within a blended learning environment provided learners with a supportive environment in which to learn mathematics. The elements which supported learning in this approach are presented.

Keywords: Blended Learning, DVD Technology, supportive learning environment

\section{Introduction}

Digital technology is pervading all levels of mathematics teaching and learning in our world. It is bringing into focus the change from conventional pencil and paper learning to a blend of technology and pencil and paper learning environments. The 2009 Incubator School Project (ISP) is one such learning environment which blends the use of DVD technology with pencil and paper in the teaching and learning of mathematics.

It has become common practice over the last few years for universities to initiate outreach programmes in order to develop secondary school learners academically, especially with regard to mathematics. Through this practice, it is hoped that, to some degree, the question of learners' under preparedness with regard to university mathematics could be successfully addressed. In so doing learners could obtain access to mathematics and science based courses in order to supply a skills need in these fields in the country.

The need for such an intervention was recognised by the Govan Mbeki Mathematics Development Unit (GMMDU) situated in the Mathematics and Applied Mathematics Department of the Nelson Mandela Metropolitan University (NMMU). In 2002 a grade 12 learner project was initiated to address the mathematics crisis, launched under the title of Incubator School Project (ISP). Grade 12 learners from schools in the surrounding areas of Port Elizabeth in the Eastern Cape were presented with mathematics sessions on Saturday mornings. The ISP targeted those grade 12 learners with potential in mathematics who wished to pursue careers in science, engineering and technology as well as mathematics and science teaching. Most of the learners who formed part of this project were from the previous 
Department of Education and Training (DET) schools. Before 1996 these schools were designated for attendance by the black community and were situated in the so called black townships. In most cases the schools that these learners attended had limited resources. While maintaining the same basic format, the ISP has undergone a number of changes since 2002 with the most significant development being the introduction of DVD technology into the programme in 2007 (Padayachee, Boshoff, Olivier, \& Harding, 2011).

\section{Methodolgy}

This research study situated within a larger action research project. The strengths of action research are those of participation and the involvement of the participants. This results in high construct validity, low refusal rates and ownership of the findings (Mouton, 2008, p151). Denscombe (2007) describes the practical nature of action research; firstlly, it is driven by a need to solve practical, real life problems; and secondly that it requires that the processes of research and action be integrated. In this research project an action research design is used since an action research design is particularly suited to research in education as it can increase understanding of what happens in particular educational contexts and it can explore the understanding of people in these contexts. In addition the cyclical, iterative process of action research is appropriate for the development of the ISPs.

The study was based on the following research question: What elements present in the DVD driven approach support the teaching and learning of mathematics? The nature of the research question justified an action research methodology since McNiff and Whitehead (2002) say that action research leads to the "... improvement of understanding and experience for social benefit".

The purpose of this research study was to determine what elements supported learning via the teaching of mathematics in a blended learning environment of the 2009 ISP therefore the researcher was interested in obtaining a detailed description of learners needs in the provision of an improved DVD driven approach within the context of blended learning. The researcher's belief is that action research studies which address important questions regarding educational practices, what works and what doesn't can add to a body of research and add theoretical understandings of teaching and learning.

There are three main sources of data for a qualitative research study, interviews, observations and documents (Merriam, 2002). This research study composed data from the questionnaires; group interviews with the learners and, facilitator reports.

The use of various methods of data collection and triangulation is vital in the determination of an in depth understanding of the programme under exploration. This also adds to the rigor, breadth and depth of the study (Creswell, 1998) and answered a broader range of questions since the researcher was not confined to one method. The researcher used interviews to see whether the results converged with the results of questionnaire. This was done to provide a more elaborate analysis and to provide a better understanding and to enhance the description.

Although qualitative data gathering methods are emphasised in this study quantitative methods were used as well. Mixed methods were employed with regard to the data collection 
and the data analysis. A mixed method approach is defined as "the type of research in which a researcher or team of researchers combines elements of qualitative and quantitative research approaches (e.g., the use of qualitative and quantitative viewpoints, data collection, analysis, inference techniques) for the broad purposes of breadth and depth of understanding and corroboration" (Johnson, Onwuegbuzie, \& Turner, 2007, p124).

In this research study the timing was concurrent since quantitative and qualitative data sets were collected, analysed and interpreted at approximately the same time. The qualitative and quantitative methods had unequal weighting with a qualitative emphasis directed by the choice of the research question that was qualitative in nature. Qualitative and quantitative data was merged. Data were collected and the two data types were analysed separately but integrated during the interpretation phase.

\section{Theoretical Framework: The 2009 ISP}

Constructivism is the paradigm underlying an intervention of this nature and the philosophy thereof will be discussed. The environment and context of the intervention needs to be considered, as these will help determine the methods to be employed in the intervention. The methods of blended learning must be explored and the approach to learning will be discussed with reference to learning cycles.

\subsection{Constructivism}

Constructivism encourages, acknowledges and accepts the fact that learners are independent. Constructivism's central idea is that human learning is constructed; the first notion is that learners construct new understandings by using what they already know and the second notion is that learning is active rather than passive (Hoover, 1996). The foregoing notions of constructivism were important in the light of the 2009 ISP since the learners had to take responsibility for and regulate their own learning outside of the $\mathrm{f} 2 \mathrm{f}$ sessions. In the light of the ISP consideration needs to be given to what synergy exists between technology and constructivism. Perkins (1992, p45) says of constructivism and technology that independently of one another they have much to offer contemporary approaches to instruction. He confirms the partnership between the two that is particularly advantageous in instructional design. Firstly the constructivist perspective places demands on the educational setting that cannot be easily met, because of a shortage of resources. Secondly "coaching-like" interactions are favoured by the constructivist agenda but with the present teacher: learner ratios this is hardly a reality. Therefore technologies offer particular help in ensuring the building of "more intimate supportive environments called for by the constructivist perspective" (Perkins, 1992, p53). In synergy, technology and constructivism focus on understanding and the active use of knowledge and skills.

Thus an intervention based on constructivism should present activities through which learners are provided with opportunities to discover and collaboratively construct meaning, learners are respected as unique individuals and are supported through the learning process. Instructors act as facilitators and dialogue and interaction between learners and facilitators should be encouraged. 


\subsection{Interactivity of the Technologies of ISP}

The researcher reflects on the interactivity of the technology used in the IS.P context.

The synchronous physical mode refers to direct, face to face (f2f), live human contact, as took place in these instances where learners gathered in one place every Saturday morning with facilitator-led classes and lectures, interactive tutorial sessions, followed by discussions, and tests. The synchronous virtual mode refers to real-time interactivity that is, seeing each other on-screen and this component was not part of the 2009 ISP and may be considered in future ISPs.

The self-paced asynchronous mode refers to forms of learning that are not live such as online learning (email, e discussions, web searching, viewing video tapes, surveys and tests). These all require an Internet connection. This possibility in the form of viewing DVDs formed part of the ISP. Off-line learning (studying using CD roms and DVDs), which is important when an Internet connection is expensive or not always available. This reflected by learners viewing DVDs outside of the contact $\mathrm{f} 2 \mathrm{f}$ time form part of this type of learning.

\subsection{The 5e Learning Cycle}

The learning cycle that is followed in the ISP is a variation on this well-documented 5e learning cycle, a research-supported method for education (Edutech Wiki, 2010). The five phases in the cycle is summarised as follows. In the ISP presentation the Engage phase is a face-to-face introduction to the topic where the learners interest is captured. This leads to the Explore phase when the DVD on a particular topic is presented and the learners' knowledge is extended as the learner constructs knowledge in the topic. Watching the DVD presentation is interspersed and followed by the Explain phase when the facilitator leads discussion and clarifies issues to refine learners understanding. The learning cycle moves into the Extend phase when learners engage with tutorial problems applying what they have learned. Before evaluation happens, learners go home equipped with the DVD and more exercises to do at home. Therefore, learners go through another, smaller learning cycle consisting again of the Explore phase when they re-watch the particular topics on DVD and the Extend phase when they do more exercises in order to prepare for the Evaluation phase when the learners' knowledge and understanding is assessed. This happens on their return the following Saturday. It is important to note that the different phases do not stand in isolation but intermingle to the need of the learner. Diagrammatically (see Figure 4.4) the learning cycle used in the ISP is as follows, starting at the top: 


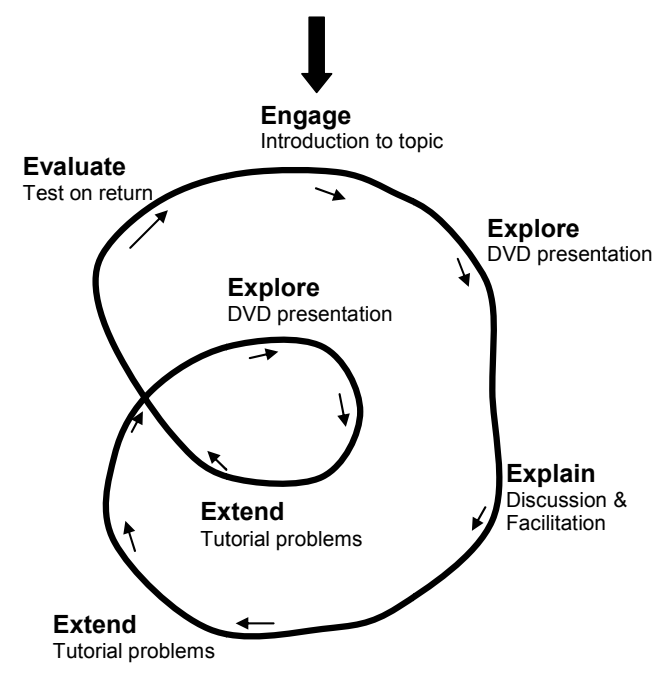

Figure 1. Learning Cycle used in 2009 ISP (Padayachee \& Harding, 2010)

\subsection{Blended Learning}

There is a shift in the educational paradigm from the rigid teacher centred approach to a learner centred approach as innovations in new technologies offer "new ways to think of producing, distributing and consuming academic material" (Seely Brown \& Duguid, 2000, p210). As technology becomes more advanced there are more opportunities for a learning centred approach. Kim (2007) asserts that the most natural form of learning is blended learning, as both traditional classroom learning and e-learning have strengths and weaknesses, and so to combine the strengths of both seems natural. Technology alone will not create the ideal learning environment (Luca, 2006). This idea is supported by Singh and Reed (2001) who cite research from Stanford University and the University of Tennessee when they suggest that blended learning is better than both traditional methods and technology alone. Blended learning incorporates different modes of delivery to enhance the learning experience and to provide the most efficient and effective instruction approach.

There are various definitions of the term blended learning, indicating the complexity, adaptability, and richness of this form of learning. Blended learning means different things to different people and therein lies its widely untapped potential (Driscoll, 2002). Pratt (2005) says that the challenge is to blend resources and activities that have the potential to enhance learning.

Although traditionally blended learning is a blend between $\mathrm{f} 2 \mathrm{f}$ and online learning, in this study blended learning is defined as a blend between $\mathrm{f} 2 \mathrm{f}$ and off line learning since the participants in this project were unable to access online learning. Therefore the definition of blended learning focus that probably best reflects the particular blended learning approach of the ISP is that proposed by Singh and Reed (2001, p2): Blended learning focuses on optimizing the achievement of learning objectives by applying the "right" learning technologies to match the "right" personal learning style to transfer the "right" skills to the "right" person at the "right" time. The principles established by this definition are the focus 
on matching the appropriate technology to achieve the learning objective, the acknowledgment of individual learning styles and the level of knowledge varies according to the individual.

\subsection{The Context}

Learners attended a series of sessions on Saturdays. The session began with the learners writing a test based on the mathematics topics covered in the previous week. Two hours were dedicated to mathematics and during this time two DVDs were presented over a period of one hour each. The DVDs were presented to learners using a DVD player connected to a data projector. The presented sessions included viewing of the DVDs and explanations by the facilitators using a tablet PC with discussions initiated by the facilitators or the learners. This was an interactive session with work on tutorial problems, peer collaborations on problems and assistance from facilitators as well as student tutors.

Learners were each given copies of the DVDs to view at their own pace at home. The intention was that in this way all learners, learning styles and learning paces would be accommodated. Hard copies of tutorial problems, additional exercises and PowerPoint slides of the lessons were given to learners for revision at home.

Two facilitators and suitably qualified student tutors assisted the facilitators during the sessions.

\subsection{Instructional Design of the DVDs}

Each DVD covered one mathematics topic and the topic was divided into micro lessons. The DVD started with an introduction and definitions of the concepts. This was followed by fully voice explained examples pertaining to that particular concept. The complete worked out solution to all examples was presented step by step, line by line and the thought process involved in the solution of the particular problem was explained by the solver. The intention was to give learners an understanding of the thought processes involved in solving a problem and to help learners who would have had no idea where to begin (Aminifar, Porter, Caladine, $\&$ Nelson, 2007). The part ended with tutorial problems to be attempted by the learner. These problems were intended to give learners a way to assess their understanding of the micro lesson. Finally, a set of comprehensive solutions followed that could be viewed independently by the learners after they had attempted the tutorial problems. This approach ensured that immediate feedback was available to any learner who had struggled with the tutorial problems. The entire DVD had voice narration integrated with animated PowerPoint slides. Any further questions or problems experienced by the learner would then be addressed at the following face to face session.

\section{Learning Environment}

It is imperative to consider the learning environment and context of the intervention within the paradigm of constructivism.

Ludtke, Robitzsch, Trautweun and Kunter (2008) state that the main underlying assumption of most educational research is that features of the learning environment, such as learning 
climate, classroom goal structures and instructional quality shape cognitive, motivational, emotional and behavioural learning outcomes. Learning environments may be seen to consist of the entire learning setting and to include the instructional processes, teacher-learner interaction, learner-learner interaction and learner attitudes (Frenzel, Pekrun, \& Goetze, 2007). It is necessary in creating a learning environment which effectively supports learning, to consider various elements.

A supportive learning environment may be defined as "the creation of a caring, rigorous and relevant learning community that provides support to all learners in aiding them to achieve their highest potential" (Holtz, 2004, pp1-2) whilst acknowledging the individual and encouraging participation and involvement (CELT, 2008).

To enhance a supportive learning environment interactive teaching methodologies must be employed. It has become evident that the use of technology in the learning environment today has become popular and is being embraced by more and more educators (Holtz, 2004).

Using the responses of learners and facilitators the researcher tabulated the elements that emerged as supportive of teaching and learning mathematics, in this 2009 ISP context. The data from learner questionnaires were ranked using statistical methods and filtered into elements. In the triangulation of this process the data from the group interviews with learners, open questions in the questionnaire and facilitators' reports were scanned for the frequency with which issues were mentioned and again filtered into elements.

In keeping with the tenets of a mixed methods analysis, the elements from the first process and the second process were integrated to determine the important elements in the context of this study.

\section{The Elements That Supported the Learning of Mathematics}

The research question set out to determine what elements were present in the DVD approach within a blended learning environment supported the learning of mathematics. Following a review of the literature on a supportive learning environment the researcher added to, adapted and established a list of elements that support learning. An analysis of the available literature from the most relevant articles indicated the main themes / clusters as important in a supportive learning environment. These themes and elements (Adapted from Thompson \& Wheeler, 2008; CELT, 2008; Holtz, 2004; Pontius \& Harper, 2006; Spencer, 1998; Martin, 2002; Ward, St Leger, Beckett, \& Harper, 1998) are summarised in the Figures 3, 4 and 5.

The majority of the elements discussed here are generic to any supportive learning environment. In a blended learning environment that employed a DVD driven approach to the teaching and learning of mathematics further elements needed to be considered and highlighted. This discussion will highlight the elements that are characteristic of this DVD approach and the elements indicative of blended learning in this context, thus leading up to answering the research question.

Thompson and Wheeler (2008) assert that all factors impacting the development of learners need to be considered when creating a learning environment. The three aspects as advocated 
by Thompson and Wheeler (2008) were used by the researcher in the analysis and interpretation of the findings in this research study. Discussion is therefore directed by the physical, intellectual and emotional aspects of the learning environment.

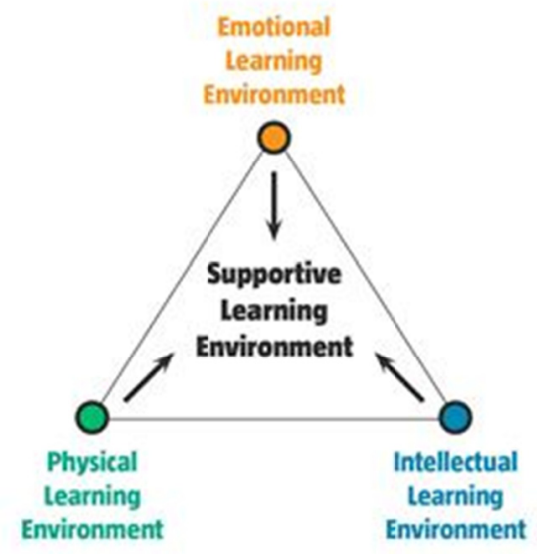

Figure 2. A Supportive Learning Environment

The characteristics of the physical learning environment consisted of the learning setting i.e. the venue used for the $2 \mathrm{f}$ sessions and the resources supplied to learners and used in the ISP. These elements of the physical learning environment impacted the learners in this study positively. Learners pointed out elements that involved the learning setting and their physical needs. To encourage collaborative learning and the effective participation in learning the furniture in the learning setting was movable, the room was comfortable in terms of cleanliness and spaciousness and the noise levels were appropriate to the activities in which the learners were engaged. The spacious, clean, noise free and technology friendly environment was welcomed by the learners. They said that this spurred them on to develop good work habits and a positive attitude towards learning. Learners also believed that the learning environment facilitated cooperative learning effectively. This allowed the learners' easy movement and access to facilitators, tutors and other learners.

Learners were provided with all their stationery requirements, and all relevant learning materials. In keeping with the tenets of blended learning, provision was made for both traditional and technology driven approaches to the teaching and learning mathematics.

The researcher discovered that in this study the money given to the learners for transport and the food provided to them played an important role in facilitating the learners' participation in the ISP. Blended learning was accomplished through the use of 'blended' physical resources. As advocated, by blended learning experts, a variety of resources were used in the ISP. In order to maximise learners' participation and performance in mathematics learners were provided with their own copy of each DVD and hardcopies of all the lectures, tutorials, additional exercises, tests, test solutions and stationery. Learners were positive that the variety of resources contributed to their successful learning of mathematics. 


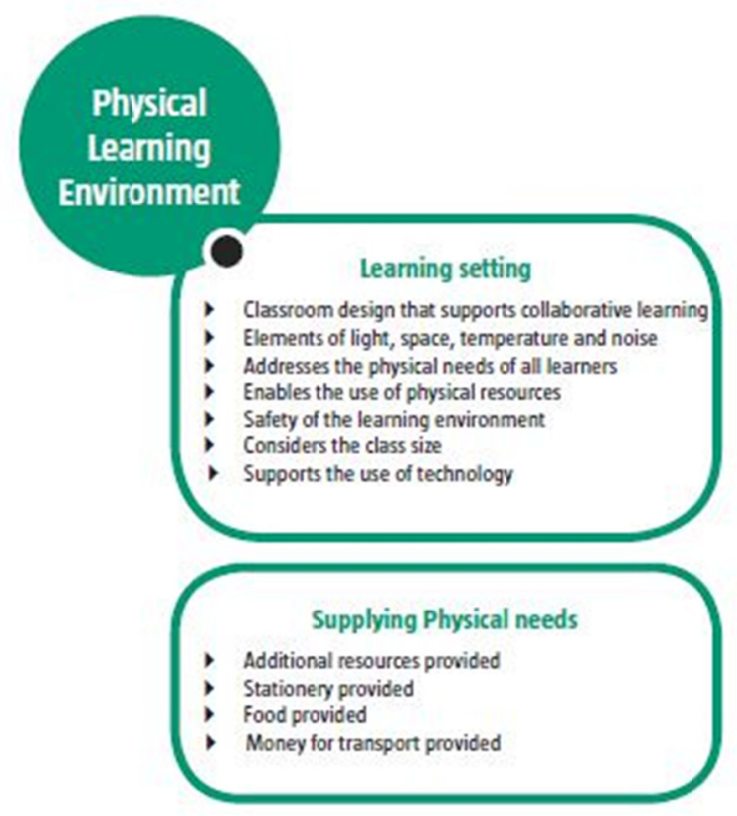

Figure 3. Elements of a Physical Learning Environment

The intellectual learning environment includes the development of a stimulating learning environment, considering appropriate teaching strategies and instructional processes, and ensuring effective interaction and assessment. The elements of such an environment should challenge all learners to be active participants in meaningful learning and allow for all learners to be given the opportunity to be successful learners.

Learners may not always know what is expected of them in a new learning environment and therefore, this needs to be clarified at the outset. With this knowledge learners can decide whether to commit to the programme from the beginning and those learners who remain will more likely participate fully therefore ensuring a successful programme. One learner echoed this view when he said, "Before selecting learners, be clear what is expected of them so that those who agree are committed and don't feel stuck in the programme. I think that it'll reduce dropouts and even if there are fewer learners you'll know it will be more successful'. The use of technology is new to many learners and this aspect needs to be introduced to them from the beginning. It is important to orientate the learners to the learning environment. For learners the most intimidating issue in learning can be the confusion created by uncertain processes or unclear outcomes.

Explanations of the different modes of delivery and the role that technology would play in the ISP were outlined. An explanation of the integration of the DVD, slides, handouts, tutorials, tests discussions and questioning was also given. At the outset of the ISP expectations for the DVD approach were communicated to the learners. Expectations for learning in this "new approach" using DVDs embedded in a blended learning environment were explained to the learners. At the beginning of each $\mathrm{f} 2 \mathrm{f}$ sessions all the outcomes of the lesson were clarified to the learners.

Clarity of outcomes and the setting out of expectations sets the tone for a supportive learning 
environment. The establishment of a non threatening environment, a culture for learning and a good work ethic was considered important in supporting learning and was encouraged.

Further activities involving problem solving, discussion, tutorial sessions and questioning all contributed to establishing a stimulating learning environment for learners. It is through active problem solving and regular work that mathematics is learned.

In keeping with the tenets of learner centredness, activities that involved active learning, problem solving and critical thinking were considered in the teaching strategies used in the ISP. Facilitators and tutors provided guided support helping learners to think through problems, encouraging them to make attempts and using the mistakes learners made to enter into discussion in keeping with the constructivist notion that learners are not consumers of content but rather they are constructors of content (Jonasson, 1991).

At the core of the DVD approach is the consideration of learners various learning styles. Since each learner had their own copy of the DVDs, they were able to access learning outside of the formal learning setting at the learners' own pace rewinding and playing sections back until they were satisfied. The DVDs were designed in such a way to be able to function as a complete unit since they completely covered each mathematics topic. Activities on the DVD engaged learners in independent learning, self reflection and the assessment and identification of their own needs. It was the intention through this to promote lifelong learning.

The instructional processes revolved around the content of the grade 12 mathematics syllabus and additional information was provided to enhance learners understanding of these mathematics concepts. To encourage a deeper approach to learning, the DVD design included comprehensive presentations of content including the contextualisation of concepts, derivations of formulae and theoretical background to concepts. These issues were not called for by the grade 12 mathematics syllabus. In addition a step by step exposition of the solutions to problems was included in the DVDs for those learners who had no idea where to begin with the problem at hand. Learners' had no contact when viewing the DVDs at home alone; and in anticipation of this shortcoming, voice explanations were given taking into account as far as possible questions and issues that might arise around the solution of a problem or the discussion of a concept.

As advocated by blended learning the instructional process of the ISP included an initial facilitation of the DVDs in the f2 $\mathrm{f}$ sessions in order to bridge any gaps in the learners' knowledge. It was through this opportunity that learners' were able to question, enter into discussion, and seek explanations. Although the DVD formed such an important component of the blended learning environment, the participants were firm that its success lies in the blending of this DVD approach with other traditional $\mathrm{f} 2 \mathrm{f}$ approaches.

Interaction played a significant role in the $\mathrm{f} 2 \mathrm{f}$ sessions of the ISP. Facilitator-learner interaction was crucial in setting an effective learning scene. This interaction ensured a non threatening learning environment, which was established where open dialogue, questions and discussions were encouraged in a non judgemental way. The facilitators' enthusiasm and the passion for mathematics inspired the learners. The tutor- learner interaction brought into play 
in addition other elements. Learners felt more comfortable with their interactions with tutors since they were close to the same age, were of the same culture as the majority of learners, and they felt motivated and inspired by the tutors' ability to do mathematics and by their success at university. Learner-learner interaction promoted peer feedback, the sharing of ideas and the techniques of problem solving and learning and collaborative work. The social interaction of the learners served to support, challenge and encourage one another.

Assessment formed an important part of the teaching and learning of mathematics in this DVD driven approach. It is through this avenue that learners could determine what their understanding of mathematics concepts were given that they have worked through the sections independently first. The forms of assessment present in this approach were self assessment via the DVD, formal assessment via the writing of weekly tests in the $\mathrm{f} 2 \mathrm{f}$ sessions and self assessment during tutorials both in the DVDS as well as in the f2 $\mathrm{f}$ sessions. The aspect of formal assessment was problematic for learners and this corroborated by the results of weekly tests. Learners' experience of the assessment on the ISP will be discussed in section.

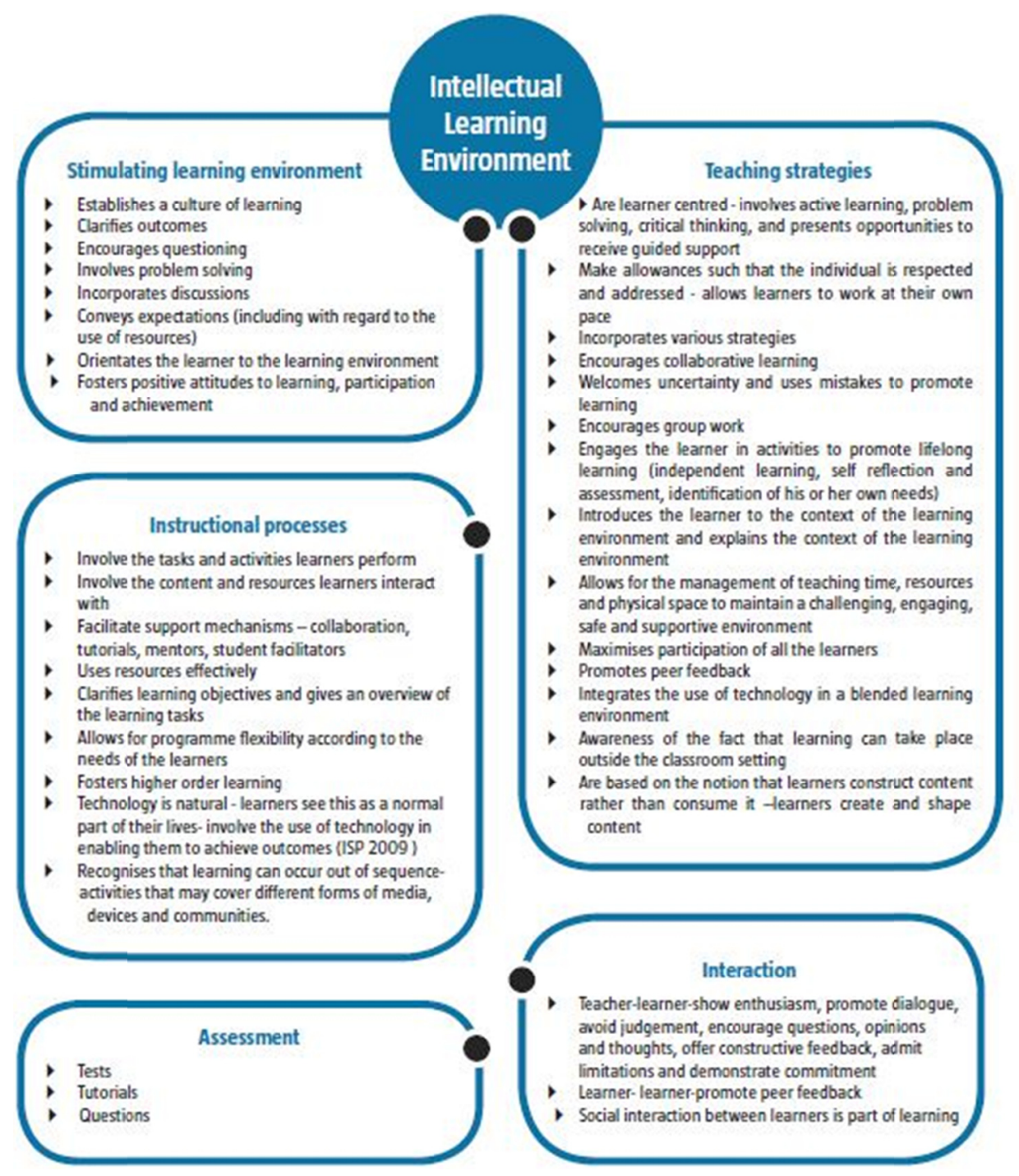

Figure 4. Elements of an Intellectual Learning Environment 


\section{MlMacrothink}

The emotional learning environment consisted of establishing the safety of learners, their personal emotional support, positive discipline and self management and the development of a sense of community. In order to effect participation a warm, safe and encouraging environment was established where clear expectations were expressed and trust developed, amongst the various role players. A sense of community was encouraged in the ISP with the aim of giving the learner a sense of belonging, and creating an environment conducive to learning mathematics. In this community, learners' individual differences with regard to learning styles were respected and different problem solving strategies and thinking were encouraged. The academic and emotional support of the learners played an important role in this community of learning.

On a more personal level facilitators and tutors acted as mentors, motivating and inspiring individual learners and thereby increasing self confidence in their ability to do mathematics, and alleviating their fears of mathematics. Research has suggested that learners may have a fear of mathematics. Their ability to do mathematics and to be motivated can increase their self confidence; and hence, their belief in their ability to do mathematics. Motivation of the learners and inculcation of positive attitudes were important to the ISP. Learners rated the element of motivation highly on their list of supportive elements of the ISP. One of the learners expressed it in this way, "the positive part of the programme was the motivational words spoken and it boosted my self confidence and I had a better understanding of mathematics". There has always been much negativity surrounding the learning of mathematics, and there are high expectations for learners to perform well in mathematics since it is a gateway subject to many of the science and technology related careers, which are so highly in demand in our economy.

Advice with regard to career choices, university requirements and proceidures was given to learners, and opportunities for career guidance and career camps were presiented to learners.

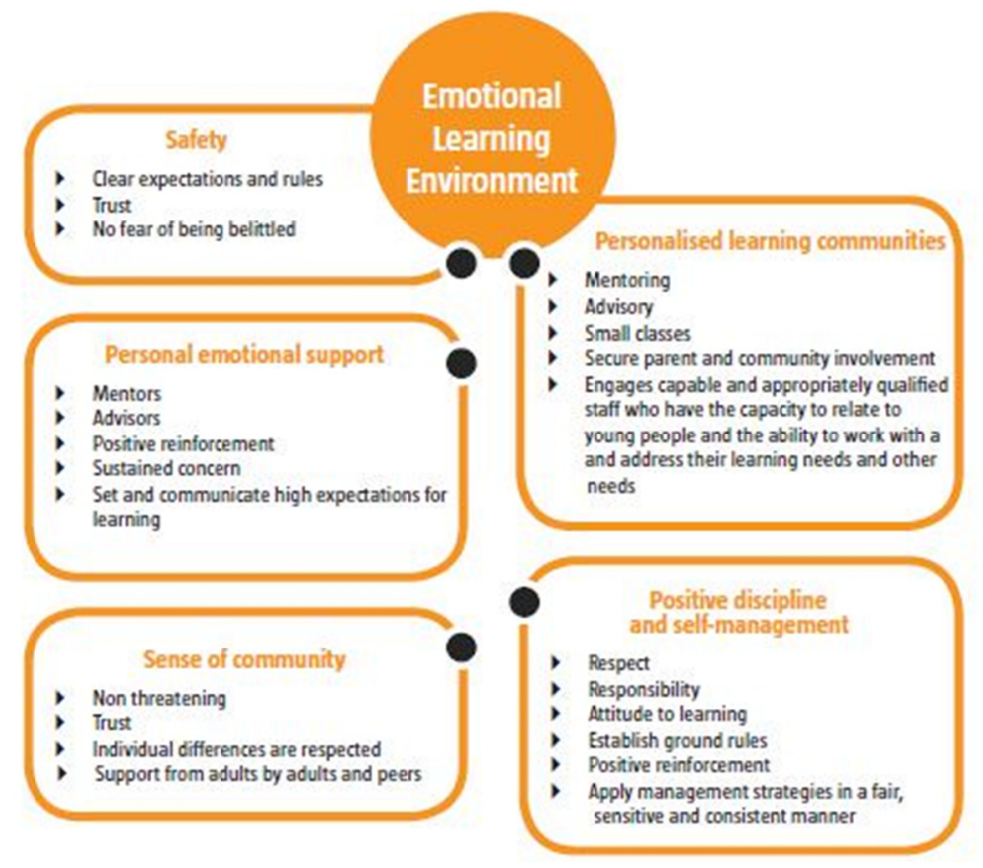

Figure 5. Elements of an Emotional Learning Environment 


\section{Conclusion}

The ISP provided a comfortable and safe environment for learners to learn. Food was provided and travel expenses were paid for. The ISP aligned its efforts with the school efforts, and engaged in communication with parents and schools. In addition the ISP learners improved their social and language skills, fostered good relationships with peers, students and facilitators. The ISP provided opportunities like engineering winter school and examination preparation sessions. Learner centred classes and cooperative learning were both used, feedbacks of assessments were individually provided. The ISP created a caring environment and held high expectations for all learners and enthusiasm, caring and an active interest in learners was an essential constituent of the ISP. The ISP provided support for all learners enabling learners to feel a sense of bonding and belonging, were academically engaged and displayed optimistic attitudes towards learning. Every learner was valuedl, high expectations were communicated to all, and positive relationships with peers were encouraged. Discipline was enforced. Positive relationships were encouraged all round and meaningful learner engagement was fostered. Finally family, school and community involvement were important features of the ISP project.

"The fact that the DVD technology is easily accessible and affordable supports a case that the DVD approach could also help to address the shortage of adequately qualified teachers and the lack of teaching resources at previously disadvantaged schools in South Africa. Solving the education crisis in South Africa is an enormous challenge and needs to be addressed at governmental level. Yet by offering workable local solutions the crisis is indeed alleviated and enables individual learners to secure a future and realise their dreams. The target group of learners is a small local group and contributes in a small way to alleviating the post-apartheid South African education crisis.” (Padayachee \& Harding, 2010).

In answering the research question and as a result of the synthesis of the research findings and conclusions the researcher summarises the contributions made by this research and presents a blended learning framework for the DVD approach. This framework is presented in Table 1.

Table 1. Framework for Blended Learning of the 2009 ISP

\begin{tabular}{|c|c|}
\hline & Framework for Blended Learning of the 2009 ISP \\
\hline 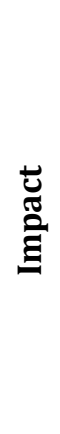 & $\begin{array}{l}\text { Improved } \\
\text { - Participation } \\
\text { - } \text { Confidence } \\
\text { - Mork ethic } \\
\text { - Motivation } \\
\text { - Mathematics understanding } \\
\text { - Language skills } \\
\text { - Problem solving skills }\end{array}$ \\
\hline
\end{tabular}




\section{Macrothink}

International Research in Education

ISSN 2327-5499

2014, Vol. 2, No. 2

\begin{tabular}{|c|c|c|c|}
\hline \multirow[t]{2}{*}{ 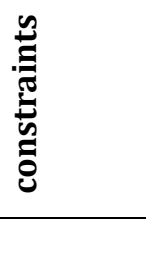 } & $\begin{array}{l}\text { - } \quad \text { Assessments not helpfu } \\
\text { - } \quad \text { Workload increased } \\
\text { - } \quad \text { Communication via DVD }\end{array}$ & ficient & \\
\hline & \multicolumn{3}{|c|}{ ELEMENTS } \\
\hline 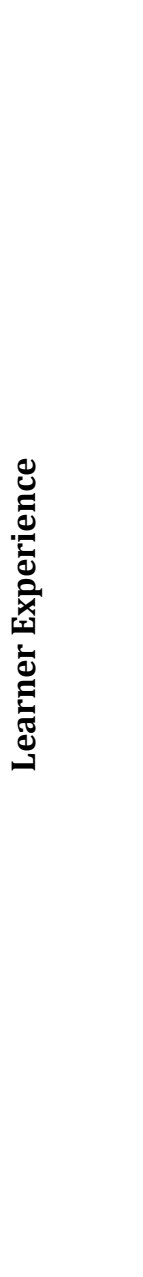 & $\begin{array}{l}\text { PHYSICAL } \\
\text { - Classroom design } \\
\text { - } \quad \text { Spacious, clean, noise free } \\
\text { environment } \\
\text { - Support use of technology } \\
\text { - Food } \\
\text { - Money }\end{array}$ & 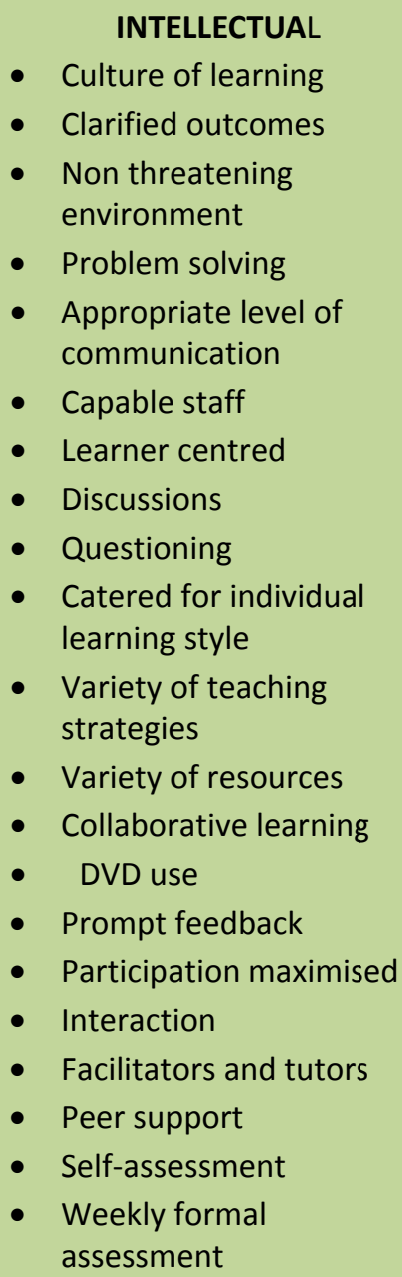 & $\begin{array}{l}\text { EMOTIONAL } \\
\text { - Clear expectations } \\
\text { - Trust developed } \\
\text { - Warm and friendly } \\
\text { environment } \\
\text { - Confidence instilled } \\
\text { - High expectations set } \\
\text { - Respect } \\
\text { - Responsibility for } \\
\text { learning } \\
\text { - Positive attitude to } \\
\text { learning } \\
\text { - Support } \\
\text { - Career guidance } \\
\text { - Mentoring }\end{array}$ \\
\hline 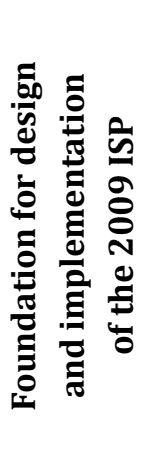 & $\begin{array}{l}\text { - } \text { Constructivism } \\
\text { - } \text { DVD approach } \\
\text { - } \text { Community of inquiry mod } \\
\text { - } 5 \text { learning cycle model } \\
\text { - High level thinking activitie } \\
\text { - } \text { Assessment } \\
\text { - } \text { Practice and application } \\
\text { - Support materials } \\
\text { - Learner responsibility for le } \\
\text { - } \text { Active participation, indepe }\end{array}$ & ing & \\
\hline
\end{tabular}




\section{References}

Aminifar, E., Porter, A., Caladine, R., \& Nelson, M. I. (2007). Creating mathematical learning resources - combining audio and visual components. Proceedings of the $7^{\text {th }}$ Biennial Engineering Mathematics and application Conference (pp. 934-956). Melbourne, Australia: MAC.

CELT. (2008). Five suggestions for the enhancement of teaching and learning. Retrieved April 22, 2010, from http://celt.tufts.edu/downloads/tipstemplatesupportiveenvironment.pdf

Frenzel, A. C., Pekrun, R., \& Goetz, T. (2007). Perceived learning environment and students' emotional experiences: A multilevel analysis of mathematics classrooms. Learning and Instruction, 17, 478-493. http://dx.doi.org/10.1016/j.learninstruc.2007.09.001

Holtz, F. (2004). Enhancing Supportive Learning Environments and Student Achievement through Project ALERT. Excerpt-ALERT Educator/Spring '06. Retrieved April 25, 2010, from http://daretodifferentiate.wikispaces.com/file/view/319_EnhancingSLE_and_SA.pdf

Hoover, W. A. (1996). The practice implications of constructivism. SEDL letter, 9(3), Retrieved May 14, 2010, from www.sedl.org/bulbs/sedletter/V09no.3/practice.html

Jonassen, D. H. (1991). Objectivism versus constructivism: do we need a new philosophical paradigm? Educational Technology Research and Development, 39(3), pp. 5-14. http://dx.doi.org/10.1007/BF02296434

Ludtke, O., Robitzsch, A., Trautwein, U., \& Kunter, M. (2008). Assessing the impact of learning environments: How to use student ratings of classroom or school characteristics in multilevel modelling. Contemporary Educational Psychology, 34(2), 120-131. http://dx.doi.org/10.1016/j.cedpsych.2008.12.001

Martin, D. (2002). Standard SEVEN - Create and maintain safe and supportive learning environments. $\quad$ Retrieved June 23, 2010, from http://teacherlearner.wordpress.com/professional-standards-for-teachers/standard-seven-creat e-and-maintain-safe-and-supportive-learning-environments/

Milne, A. J. (2006). Designing Blended Learning Space to the Student Experience. In D. G. Oblinger (Ed.), Learning Spaces. Retrieved September 23, 2010, from www.educause.edu/learningspaces

Perkins, D. N. (1992). Technology meets Constructivism: Do they make a marriage? In T. M. Duffy \& D. H. Jonassen (Eds.), Constructivism and the Technology of Instruction: A Conversation. Lawrence Erlbaum associates publishers: New Jersey.

Pontius, J. L., \& Harper, S. R. (2006). Principles for good practice in graduate and professional student engagement. New Directions for Student Services. No 115. San Francisco: Jossey-Bass.

Spencer, K. L. (1998). Purposeful teaching: Design and instruction for adult learners. Retrieved June 1, 2009, from http://www.rcmp-learning.org/docs/ecdd1140.htm 


\section{Macrothink}

Thompson, N. E., \& Wheeler, J. P. (2008). Learning environment: Creating and implementing a safe, supportive learning environment. Journal of Family \& Consumer Sciences Education, 26(2), 33-43.

Ward, K., St Leger, P., Beckett, D., \& Harper, G. (1998). Providing Education and Training for At-Risk and Unemployed Young People, Successful Learning Project, Department of Education, Victoria.

\section{Copyright Disclaimer}

Copyright reserved by the authors.

This article is an open-access article distributed under the terms and conditions of the Creative Commons Attribution license (http://creativecommons.org/licenses/by/3.0/). 